\title{
Attitudes and Perceptions of Healthcare Providers and Medical Students Towards Clinical Pharmacy Services in United Arab Emirates
}

\author{
Eman Abu-Gharbieh ${ }^{1^{*}}$, Sahar Fahmy ${ }^{2}$, Bazigha Abdul Rasool ${ }^{1}$, \\ Abduelmula Abduelkarem ${ }^{3}$ and Iman Basheti ${ }^{4}$ \\ ${ }^{1}$ Dubai Pharmacy College, Dubai, United Arab Emirates, ${ }^{2}$ Helwan University, Helwan, Egypt, ${ }^{3}$ Ajman University of \\ Science and Technology, Ajman, United Arab Emirates, ${ }^{4}$ University of Applied Science, Amman, Jordan
}

\begin{abstract}
Purpose: To explore healthcare providers' (HCPs) and medical students' attitudes to, and perceptions of the pharmaceutical services that clinical pharmacists can provide in United Arab Emirates.

Methods: A total of 535 participants (265 HCPs and 270 medical students) were asked to complete a questionnaire over a period of three months (January through March 2009).

Results: Almost three quarters of the students perceived that the clinical pharmacist is an important part of the healthcare team while $82 \%$ believed that clinical pharmacists can help improve the quality of medical care in hospitals. Eighty one percent of medical students expressed confidence in the ability of clinical pharmacists to minimize medication errors. Although slightly more than half of the respondents $(53 \%)$ reported that they did not have clinical pharmacy services in their institutions, there was substantial willingness among physicians and nurses to cooperate with clinical pharmacists. The majority of physicians (92\%) and nurses (87\%) expressed the view that the clinical pharmacist is an important integral part of the healthcare team.

Conclusion: The HCPs and medical students in the study setting valued the role of clinical pharmacists in healthcare delivery. However, new developments in pharmacy services in the UAE hospital setting is recommended for adoption in hospitals.
\end{abstract}

Key words: Clinical pharmacy services, Pharmaceutical care, Perception, Healthcare providers. 


\section{INTRODUCTION}

Clinical pharmacy is a health science discipline whereby pharmacists provide patient care that optimizes medication therapy and promotes health, wellness, and disease prevention [1]. This field of pharmacy practice focuses on patient-oriented rather than drug product-oriented service [2]. The discipline arose out of dissatisfaction with old practice norms and the pressing need for a competent health professional with a comprehensive knowledge in the therapeutic use of drugs. Clinical pharmacists are a primary source of scientifically valid information and advice regarding the safe, appropriate, and cost-effective use of medications [1,3-5]. Already, the level of interaction between physicians and pharmacists in the developed world is high, resulting in safer, more effective, and less costly drug therapy [3].

Many studies have shown that physicians are receptive to several clinical services provided by pharmacists if these services were provided in the form of consultation or in a supportive role [4-7]. Still, however, the relationship between the physician and community pharmacist has been described as a 'complex one' [3,8-13] and some studies have reported the existence of communication gap between pharmacists and medical doctors [14.15].

Studies have been conducted in some Arab countries to assess physicians' acceptance of the clinical pharmacists' role. In Kuwait, patient care, which involves interaction with and observation of the patient, is still exclusively delivered by physicians and nurses, with the pharmacists' input in managing drug therapy dependent on the physician's willingness to accept that role [16]. In Sudan, physicians were found to be 'uncomfortable' with pharmacists suggesting or recommending prescription medications to their patients, even if it involved the treatment of minor illnesses [17] but in Jordan, the situation was different, as $63 \%$ of physicians expected the pharmacist to educate their patients with regard to the safe and appropriate use of drugs. In addition, approximately half of the physicians agreed that pharmacists were always a reliable source of drug information [18]. In contrast, although the role of the community pharmacist seems to be changing in many countries, $48.2 \%$ of physicians in Kuwait are still uncomfortable with pharmacists suggesting the use of prescription medications to patients. Furthermore, one third of physicians do not expect the pharmacist to be available for consultation during rounds [19]. Doctors and community pharmacists have little interaction in Libya and UAE, based on the findings of one particular study [20] which showed that almost 70 and $60 \%$ of doctors in Libya and UAE, respectively, either 'rarely' or 'never' discussed patients' drug therapy with a pharmacist. Furthermore, it would appear that there is some skepticism about the appropriateness of pharmacists being involved in monitoring blood pressure and providing a therapeutic substitute.

In UAE, due to the increasing demand for pharmacy professionals, seven pharmacy schools offering bachelor's degree in pharmacy were established across the emirates. Pharmacy education commenced in UAE in 1992 with the establishment of Dubai Pharmacy College. Since then more pharmacy training programs have been put in place to meet the high demand for pharmacists in the country. In October 2008, Gulf Medical University launched the Doctor of Pharmacy (PharmD) program but no pharmacy school has commenced any postgraduate clinical pharmacy program in UAE.

Pharmacists in the UAE practice in various settings, including community pharmacy, hospital pharmacy, drug information service, pharmaceutical industry, marketing, sales, regulatory agencies, academia, and drug 
distribution. Many are being recruited from other countries to meet the high demand for pharmacy professionals in all practice areas. There are few clinical pharmacists working in the public sector in UAE and virtually none in the private sector. Thus, clinical pharmacy is still in its early stage of development in the UAE and, therefore, requires greater attention to achieve the objective of pharmaceutical care [21].

The objective of this study was to investigate the level of acceptance of integrating clinical pharmacists into the primary healthcare team. This was carried out by assessing the perception of physicians, nurses, pharmacists as well as medical colleges' students regarding the clinical pharmacists' roles and responsibilities in providing better pharmaceutical care to patients in the UAE. In addition, we aimed to identify the obstacles that hinder such integration and suggest ways to overcome these obstacles.

\section{METHODS}

The study was conducted in three randomly selected hospitals and six health-related science colleges in four different universities: Gulf Medical University, Sharjah University, Dubai Pharmacy College and Dubai Medical College for Girls. The participants were randomly selected from lists provided by their facility administrators. The questionnaires were distributed to 300 health care professionals and 300 medical students. The participants were approached either directly or via telephone interview to arrange a 15minutes interview with the researcher at a convenient time. The questionnaire was completed by the participants under the supervision of the researcher in order to improve clarity and limit response bias.

The questionnaire included both closed and open questions and statements, and consisted of a series of questions prepared by the researchers with one version targeted at HCPs and the other at students. To ensure face validity, the questionnaire was sent to three academics and three physicians with a wide range of professional experience. Their views and comments were considered and then incorporated, where appropriate, into the final versions of the questionnaire. To assess test-retest reliability, the questionnaire was administered on two occasions to 12 randomly selected HCPs. The second testing took place two weeks after, and was not included in the final survey analysis. Testretest reliability was calculated using Spearman's correlation coefficient $(r)$. The rho-value was 0.82 , which implies acceptable test-retest reliability.

Respondents were asked to answer a question using the options "yes" or "no", or to rate their response using the options, "agree", "neutral", or "disagree". There was a section inviting comments at the end of the questionnaire. The study was carried out over a period of three months (January to March 2009).

\section{Data analysis}

The participants' responses were encoded and the data were analyzed using Statistical Package for the Social Sciences (SPSS, version 17, Chicago, IL, US). Three categories of the relevant responses were used so that $95 \%$ confidence intervals could be calculated. Descriptive analysis was used to calculate the proportion of each group of respondents who agreed/disagreed with each statement in the questionnaire. Chi square test was used to identify any significant difference among the participants' responses regarding certain statements in the questionnaire with a significant level of $p$ value of $<0.05$.

\section{RESULTS}

Three hundred questionnaires were distributed to both HCPs and health sciences-related students. A total of 270 students and 265 HCPs - 103 pharmacists, 71 physicians, and 91 medical assistants (nurses) - completed the questionnaire. 
Response rates of 90.0 and $88.3 \%$ were recorded for medical students and HCPs, respectively.

\section{Students' perception}

Table 1 summarizes the data obtained in respect of students who gave their opinions in response to the questions or statements included in the survey. The respondents were $132(49 \%)$ female and $137(51 \%)$ male. Among them were 71 (26\%) pharmacy college students, 94 (35\%) medical college students, $57(21 \%)$ dental college students and 38 (14\%) nursing college students.

The majority of the respondents 199 (74\%) perceived that the clinical pharmacist is an important part of the medical team while 221 (82 \%) believed that clinical pharmacists can help improve the quality of medical care in a hospital setting. When the students were asked about the ability of clinical pharmacists to minimize medication errors and improve patient therapeutic outcomes, $217(81 \%)$ of them agreed with the statement.
The majority of the respondents $(221,82 \%)$ reported that their institutions do not offer clinical pharmacy or PharmD degree programs. However, 173 (64\%) reported that they had heard of such programs during the course of their studies. One hundred eighty one $(67 \%)$ of the students agreed that clinical pharmacists should be allowed to acquire training and qualifications in certain medical areas to enable them effectively discharge the responsibility of patient counselling in chronic illnesses.

Of all the respondents, only 146 (54\%) of the students perceived that the presence of clinical pharmacists will be accepted by other healthcare staff in their daily practice. A minority of students (104, $39 \%$ ) believed that there is increasing interest in UAE in clinical pharmacy as a profession while more than half of the students $(154,57 \%$ ) believed that there is increased interest in clinical pharmacists serving on the healthcare team in order for a hospital to secure accreditation.

Table 1: Data obtained in respect of student respondents who gave their opinions on the statements included in the survey $(n=270)$.

\begin{tabular}{|c|c|c|c|}
\hline Statement & $\begin{array}{l}\text { Agree } \\
\text { n (\%) }\end{array}$ & $\begin{array}{l}\text { Neutral } \\
\text { n (\%) }\end{array}$ & $\begin{array}{l}\text { Disagree } \\
\text { n (\%) }\end{array}$ \\
\hline Previously heard about clinical pharmacy programs & $173(64)$ & - & $97(36)$ \\
\hline $\begin{array}{l}\text { The clinical pharmacist is an important and integral part of the } \\
\text { medical team }\end{array}$ & $199(74)$ & $66(24)$ & $5(2)$ \\
\hline $\begin{array}{l}\text { The clinical pharmacist can improve the quality of medical care in } \\
\text { a hospital setting. }\end{array}$ & $221(82)$ & $40(15)$ & $9(3)$ \\
\hline $\begin{array}{l}\text { The clinical pharmacist can acquire training in certain medical } \\
\text { areas enabling them to perform patient counseling }\end{array}$ & $181(67)$ & $73(27)$ & $16(6)$ \\
\hline $\begin{array}{l}\text { Clinical pharmacists as part of medical teams is essential for } \\
\text { hospital accreditation }\end{array}$ & $154(57)$ & $98(36)$ & $18(7)$ \\
\hline $\begin{array}{l}\text { Clinical pharmacists as part of medical teams will minimize } \\
\text { medication errors and improve patient therapeutic outcomes }\end{array}$ & $217(81)$ & $44(16)$ & $9(3)$ \\
\hline $\begin{array}{l}\text { There is increasing interest in clinical pharmacy as a profession } \\
\text { in UAE }\end{array}$ & $104(39)$ & $118(43)$ & $48(18)$ \\
\hline $\begin{array}{l}\text { Doctors and other healthcare staff will accept the involvement of } \\
\text { clinical pharmacists in patient management and providing extra } \\
\text { services within the framework of clinical pharmacy }\end{array}$ & $146(54)$ & $96(36)$ & $28(10)$ \\
\hline
\end{tabular}

$p<0.001$ (Agree vs Disagree) 


\section{Healthcare providers' perceptions}

Ninety seven (37\%) of the HCPs were citizens of UAE while the rest $(186,63 \%)$ were of other nationalities. The respondents were 149 (56 \%) female and 116 (44\%) male. One hundred twenty five (47\%) of the respondents were less than 35 years old and $121(46 \%)$ were in the age bracket of $36-46$ years. With regard to respondents' professions, 103 (39\%) were pharmacists, 71 (27\%) physicians and 91 (34\%) nurses. Of the total, 103 (39\%) reported that they obtained their first professional degree or qualification from either USA or a European country while 57 (22\%) and 105 (40\%) of the respondents stated that their first professional qualification was acquired in UAE and Eastern Asia, respectively. Participants' demographic information is shown in Table 2.

Table 2: Healthcare workers' demographic information $(n=265)$

\begin{tabular}{ll}
\hline Demographic information & $\mathbf{n}(\%)$ \\
\hline $\begin{array}{l}\text { Gender } \\
\text { Male }\end{array}$ & $116(43.8)$ \\
$\quad$ Female & $149(56.2)$ \\
Age distribution & \\
$\quad$ Less than 35 yeas & $125(47.2)$ \\
$\quad(36-46)$ years & $121(45.7)$ \\
Nationality & \\
UAE citizens & $97(36.6)$ \\
Other nationalities & $168(63.4)$ \\
Profession & \\
$\quad$ Pharmacy & $103(38.9)$ \\
Physician & $71(26.8)$ \\
$\quad$ Nurse & $91(34.3)$ \\
Professionally qualified in & \\
$\quad$ USA/Europe & $103(38.9)$ \\
$\quad$ UAE & $57(21.5)$ \\
Other countries & $105(39.6)$ \\
\hline
\end{tabular}

The majority of HCPs (253, $95.5 \%)$ reported that the clinical pharmacist is an important integral part of the clinical ward team. HCPs perception was high and was not significantly dependent on their professions. However, respondents' belief in clinical pharmacists' capacity to improve the quality of patient care in a hospital setting was relatively less with only three-quarters of HCPs agreeing. In addition, $196(74.0 \%)$ of respondents perceived that the clinical pharmacist is able to minimize medication error and improve patient therapy outcomes.

Two hundred and forty five $(92.5 \%)$ of the respondents believe that clinical pharmacy representation in pharmacy and therapeutic committees is essential while 226 (85.3\%) stated that the presence of clinical pharmacists in a clinical ward team is a requirement for hospital accreditation.

There is a strong view that the clinical pharmacist can obtain training in certain medical specialty areas to enable them perform patient counselling $(243,92.0 \%)$ and play a role in patient medication education (249, $94.0 \%)$. The perception of clinical pharmacists' role in patient medication education varied among the different professions studied with 81 (89\%) of the nurses saying that clinical pharmacists could play a role in patient medication education compared with 102 (99\%) of pharmacists.

Although the majority of other respondents $(253,95.5 \%)$ reported their willingness to cooperate with the clinical pharmacist, however, when they were asked whether there was increasing interest in clinical pharmacy services in UAE, only about half (148, $55.9 \%)$ agreed. On the other hand, under a third $(78,29.4 \%)$ of HCPs agreed with the statement that the clinical pharmacist has fulfilled his/her role in UAE.

Table 3 shows the data in respect of HCP respondents who provided their on the statements put to them in the survey. With regard to HCPs' perception of clinical pharmacists' role, there was a significant difference in their responses on the issue of the clinical pharmacists bringing improvement 
Table 3: Perception of HCP respondents who agreed or not with the statements put to them in the survey $(n=265)$

\begin{tabular}{|c|c|c|c|c|c|}
\hline Statement & HCP & $\begin{array}{c}\text { Agree } \\
\text { n; } \%(95 \% \mathrm{Cl})\end{array}$ & $\begin{array}{c}\text { Neutral } \\
\%\end{array}$ & $\begin{array}{c}\text { Disagree } \\
\%\end{array}$ & $\begin{array}{c}p- \\
\text { value }\end{array}$ \\
\hline \multirow{4}{*}{$\begin{array}{l}\text { Healthcare professionals' willingness to } \\
\text { cooperate with the clinical pharmacist }\end{array}$} & Pharmacists & $97 ; 94(90-99)$ & 0 & 6 & \multirow[t]{4}{*}{0.418} \\
\hline & Physicians & $67 ; 94$ (89-100) & 0 & 6 & \\
\hline & Nurses & $89 ; 98(95-100)$ & 0 & 2 & \\
\hline & Total & $253(95.47)$ & & & \\
\hline \multirow{4}{*}{$\begin{array}{l}\text { The clinical pharmacist is an important } \\
\text { integral part of the clinical ward team }\end{array}$} & Pharmacists & $96 ; 93$ (88-98) & 6 & 1 & \multirow[t]{4}{*}{0.656} \\
\hline & Physicians & $65 ; 92(85-98)$ & 7 & 1 & \\
\hline & Nurses & $79 ; 87$ (80-94) & 11 & 2 & \\
\hline & Total & $240(90.57 \%)$ & & & \\
\hline \multirow{4}{*}{$\begin{array}{l}\text { The clinical pharmacist can improve the } \\
\text { quality of patient care in a hospital } \\
\text { setting }\end{array}$} & Pharmacists & 83; 81(73-88) & 18 & 1 & \multirow[t]{4}{*}{0.154} \\
\hline & Physicians & $54 ; 76(66-86)$ & 23 & 1 & \\
\hline & Nurses & $61 ; 67$ (57-77) & 33 & 0 & \\
\hline & Total & $198(74.7 \%)$ & & & \\
\hline \multirow{3}{*}{$\begin{array}{l}\text { The clinical pharmacist can acquire } \\
\text { training in certain medical areas to } \\
\text { perform patient counseling }\end{array}$} & Pharmacists & 98; 95 (91-99) & 5 & 0 & \multirow[t]{3}{*}{0.387} \\
\hline & Physicians & $64 ; 90(83-97)$ & 10 & 0 & \\
\hline & $\begin{array}{c}\text { Nurses } \\
\text { Total }\end{array}$ & $\begin{array}{c}81 ; 89(83-95) \\
243(92.0 \%)\end{array}$ & 10 & 1 & \\
\hline \multirow{4}{*}{$\begin{array}{l}\text { The clinical pharmacist in a clinical } \\
\text { ward team is a requirement for hospital } \\
\text { accreditation }\end{array}$} & Pharmacists & $86 ; 84$ (76-91) & 15 & 1 & \multirow[t]{4}{*}{0.622} \\
\hline & Physicians & $63 ; 89$ (81-96) & 9 & 2 & \\
\hline & Nurses & $77 ; 85$ (77-92) & 13 & 2 & \\
\hline & Total & $226(85.28)$ & & & \\
\hline \multirow{4}{*}{$\begin{array}{l}\text { The clinical pharmacist is able to } \\
\text { minimize medication error and improve } \\
\text { patient therapy outcomes }\end{array}$} & Pharmacists & $74 ; 72(63-81)$ & 22 & 6 & \multirow[t]{4}{*}{0.693} \\
\hline & Physicians & $57 ; 80$ (71-90) & 17 & 3 & \\
\hline & Nurses & $65 ; 71(62-80)$ & 23 & 6 & \\
\hline & Total & $196(74.0 \%)$ & & & \\
\hline \multirow{4}{*}{$\begin{array}{l}\text { There is increased interest in clinical } \\
\text { pharmacy services in UAE }\end{array}$} & Pharmacists & $61 ; 59(50-69)$ & 32 & 9 & \multirow[t]{4}{*}{0.576} \\
\hline & Physicians & $35 ; 49(38-61)$ & 35 & 16 & \\
\hline & Nurses & $52 ; 57$ (47-67) & 30 & 13 & \\
\hline & Total & $148(55.9 \%)$ & & & \\
\hline \multirow{4}{*}{$\begin{array}{l}\text { Clinical pharmacy representation in } \\
\text { therapeutic policy committee and } \\
\text { clinical ward rounds is desirable }\end{array}$} & Pharmacists & $95 ; 92$ (87-97) & 7 & 1 & \multirow[t]{4}{*}{0.410} \\
\hline & Physicians & $69 ; 97$ (93-100) & 3 & 0 & \\
\hline & Nurses & $81 ; 89(83-95)$ & 10 & 1 & \\
\hline & Total & $245(92.5 \%)$ & & & \\
\hline \multirow{4}{*}{$\begin{array}{l}\text { The clinical pharmacist has a role in } \\
\text { patient medication education }\end{array}$} & Pharmacists & $102 ; 99(97-100)$ & 1 & 0 & \multirow[t]{4}{*}{0.05} \\
\hline & Physicians & $66 ; 93(87-99)^{\prime}$ & 7 & 0 & \\
\hline & Nurses & $81 ; 89$ (83-95) & 10 & 1 & \\
\hline & Total & $249(94.0 \%)$ & & & \\
\hline \multirow{4}{*}{$\begin{array}{l}\text { The clinical pharmacist has fulfilled } \\
\text { his/her role in UAE }\end{array}$} & Pharmacists & $28 ; 27$ (19-36) & 42 & 31 & \multirow[t]{4}{*}{0.054} \\
\hline & Physicians & $18 ; 25$ (15-35) & 31 & 44 & \\
\hline & Nurses & $32 ; 35(25-45)$ & 43 & 22 & \\
\hline & Total & $78(29.4 \%)$ & & & \\
\hline
\end{tabular}

Chi-square test, $p<0.05 ;(n=103,71$ and 91 for pharmacists, physicians and nurses, respectively); HCP = healthcare professional 
Table 4: Respondents' responses on some roles of the clinical pharmacist

\begin{tabular}{llccccc}
\hline & \multicolumn{5}{c}{ Country where medical qualification was obtained } \\
\cline { 2 - 7 } Statement & & $\begin{array}{c}\text { UAE } \\
\mathbf{n}(\%)\end{array}$ & $\begin{array}{c}\text { USA } \\
\text { n (\%) }\end{array}$ & $\begin{array}{c}\text { Eastern Asia* } \\
\text { n (\%) }\end{array}$ & $\begin{array}{c}\text { Europe } \\
\text { n (\%) }\end{array}$ & p-value \\
\hline $\begin{array}{l}\text { The presence of the clinical } \\
\text { pharmacist in a clinical ward } \\
\text { team will improve the quality } \\
\text { of patient care in a hospital }\end{array}$ & Agree & $33(58)$ & $45(75)$ & $86(81)$ & $34(81)$ & \\
$\begin{array}{l}\text { setting } \\
\text { I think that the clinical } \\
\text { pharmacist able to minimize } \\
\text { medication errors, maximize }\end{array}$ & Neutral & $24(42)$ & $15(25)$ & $19(18)$ & $7(17)$ & 0.017 \\
$\begin{array}{l}\text { cost-effectiveness and } \\
\text { improve patient outcomes }\end{array}$ & Neutral & $12(21)$ & $13(22)$ & $23(19)$ & $8(7.0)$ & 0.913 \\
\hline
\end{tabular}

* India, Pakistan, Philippine and Bangladesh.

Table 5: Further respondents' responses on the ability of the clinical pharmacist to minimize medication errors, maximize cost-effectiveness and improve patients' drug therapy outcomes if clinical pharmacy services are available

\begin{tabular}{lcccccc}
\hline & & $\begin{array}{c}\text { Agree } \\
\mathbf{n}(\%)\end{array}$ & $\begin{array}{c}\text { Neutral } \\
\mathbf{n}(\%)\end{array}$ & $\begin{array}{c}\text { Disagree } \\
\mathbf{n}(\%)\end{array}$ & Total & $p$-value \\
$\begin{array}{lcccccc}\text { Do you have a clinical } \\
\text { pharmacist in your } \\
\text { institution? }\end{array}$ & Yes & $102(82)$ & $17(14)$ & $6(5)$ & 125 & \\
\cline { 2 - 5 } & No & $94(67)$ & $39(28)$ & $7(5)$ & 140 & \\
& & 196 & 56 & 13 & 265 & \\
Total & & & & & &
\end{tabular}

to the quality of patient care $(p<0.05)$ in relation to the country where they obtained their medical qualifications from (Table 4). However, there was no significant difference in their responses in relation to their nationality and gender. In addition, there was no significant difference $(p>0.05)$ in their responses (in relation to the part of the world they obtained their professional qualifications) when it came to the issue of the clinical pharmacist's ability to minimize medication error and improve patient therapy outcomes.

Interestingly, as Table 5 shows, having a clinical pharmacist in the respondent's institution significantly affected $(p<0.05)$ the responses of the participants to the statement that participation of the clinical pharmacist in the clinical ward team will minimize medication errors and improve patient therapy outcomes.

\section{DISCUSSION}

The practice of pharmacy has changed significantly in recent years. This, invariably, will necessitate changes in procedures and training, and may require more resources, imaginative use of pharmacy skills, and involvement of clinical pharmacists at prescribing and dispensing stages [22]. In spite of the interest in increased professionalization of many pharmacy services, is there sufficient will amongst pharmacists generally to make the change 
that is necessary? Are pharmacists willing to be more professional and extend their role?

Interestingly, there is a strong belief among medical college students that clinical pharmacists are an important part of the clinical team and are able to minimize medication errors in a hospital setting. More than half $(54 \%)$ of them agreed that doctors and other HCPs will accept the pharmacists to provide additional services within the framework of clinical pharmacy. The study revealed that only two-thirds of the medical students knew about the clinical pharmacy program in their institutions during their study period. This may be attributed to the absence of patient-oriented PharmD program or the fact that most of the clinical pharmacy courses are delivered in the last year of the pharmacy programs of the colleges of pharmacy in UAE. Only $39 \%$ students perceived that there is increased interest in clinical pharmacy services in UAE. This should attract the attention of health care facilities to the need to recruit and expand the role of clinical pharmacists in order to provide the better pharmaceutical patient care. In a previous study in UAE, it was reported that there a shortage of clinical pharmacists serving in hospitals exists [23], which necessitate the need for clinically-oriented training programmes for pharmacists and pharmacy students to overcome this shortage and to enhance pharmacists' role in improving patient care in hospital settings.

Healthcare providers (HCPs) in UAE showed a high perception of the role of clinical pharmacists in improving therapeutic patient outcomes. This study also revealed that HCPs expected pharmacists to assume an important role in direct patient care especially by playing a supportive role in therapeutic treatment and in patient education and counseling. Other healthcare professionals, to a certain extent, appreciate the role of the pharmacist in the hospital setting with up to three-quarters of them stating that clinical pharmacists can help to improve the quality of patient care in the hospital setting. There is a previous report which indicated that pharmacists working in hospitals managed by international institutions, such as Johns Hopkins and Cleveland Clinic, provided more professional clinical pharmacy services where clinical pharmacists were involved in patient medication review and therapy management [24].

Resistance of physicians to the role of the clinical pharmacists has been reported in some studies [20;25]. While the situation in UAE may be comparable in some ways to that in the United States, it is somewhat different from those in other Arab countries, such as Kuwait, where physicians showed resistance to the role of clinical pharmacists, and this was attributed to lack of physicians' exposure to pharmacists participating in clinical activities[16]. To overcome this resistance, development and incorporation of courses related to inter-professional relationships between physicians and pharmacists in medical and pharmaceutical education curricula should enhance collaboration between physicians and pharmacists in the provision of patient care.

Although our findings indicate that HCPs generally expressed belief that clinical pharmacists have fulfilled their role in UAE, this is applicable only to the health care facilities managed by the government. This is due to the virtual lack of clinical pharmacists in private hospitals in UAE [21]. Clinical pharmacy services are provided in most of governmental hospitals in UAE. These hospitals are managed by international institutions which have incorporated clinical pharmacy services in their patient care. Private hospital proprietors should do likewise by first hiring clinical pharmacists to become part of their clinical ward teams.

Findings from this study also further support the need for clinical pharmacists to perform specific duties that have been suggested in previous studies, e.g., patient education and minimizing medication errors [26]. Physicians and nurses in UAE clearly support 
the participation of the clinical pharmacist in the clinical ward team work from whom they can regularly seek advice with regard to patient medication. The results also reinforce the importance of the specialized role of the clinical pharmacist as well as the fact that HCP resistance should not constitute a barrier to instituting clinical pharmacy services in UAE hospitals.

\section{Limitations of the study}

Although the response rate was high, the study has some limitations with regard to the small sample size of respect of participants' area of specialization. In addition, HCPs random sampling was not done based on categorization of their facilities which may have an impact on the need for clinical pharmacy services.

\section{CONCLUSION}

This study showed that HCPs were willing to collaborate with clinical pharmacists in monitoring drug therapy and improving patient care by identifying medication errors. Consequently, new measures to promote and extend clinical pharmacy services in both governmental and private hospitals in UAE should be adopted and implemented in UAE. Attention to to the institution of clinicallyoriented training programmes for pharmacists and pharmacy students in order to overcome the present shortage of clinical pharmacists in the country. Increasing inter-professional relationships between physicians and pharmacists in medical and pharmaceutical education curricula is also needed to enhance collaboration between physicians and pharmacists in patient care.

\section{ACKNOWLEDGMENTS}

The authors would like to thank Prof. Saeed Ahmed Khan, Dean of Dubai Pharmacy College, for facilitating this project. Special thanks also go to the undergraduate pharmacy students who helped in the distribution and collection of the surveys:
Jenen Abdelfattah, Reem FarajAllah and Safa'a Bkairat

\section{REFERENCES}

1. American College of Clinical Pharmacy. The definition of clinical pharmacy. Pharmacotherapy 2008; 28: 816-817.

2. Barker KN, Valentino JG. On a political and legal foundation for clinical pharmacy practice. J Am Pharm Assoc 1972; 12: 202-206.

3. Leape LL, Cullen DJ, Clapp MD, Burdick E, Demonaco HJ, Erickson Jl, Bates DW. Pharmacist participation on physician rounds and adverse drug events in the intensive care unit. JAMA 1999; 282: 267-270.

4. Bond CA, Raehl CL, Franke T. Clinical pharmacist staffing in United States hospitals. Pharmacotherapy 2002; 22: 1489-1499.

5. Bero LA, Mays NB, Barjesteh $K$, Bond $C$. Expanding the roles of outpatient pharmacists: effects on health services utilisation, costs, and patient outcomes. Cochrane Database Syst Rev 2000; 336.

6. Haxby DG, Weart CW, Goodman BW, Jr. Family practice physicians' perceptions of the usefulness of drug therapy recommendations from clinical pharmacists. Am J Hosp Pharm 1988; 45: 824-827.

7. Cowen DL. Changing relationship between pharmacists and physicians. Am J Hosp Pharm 1992; 49: 2715-2721.

8. Sulick JA, Pathak DS. The perceived influence of clinical pharmacy services on physician prescribing behavior: a matched-pair comparison of pharmacists and physicians. Pharmacotherapy 1996; 16: 1133-1141.

9. Morley A, Jepson MH, Edwards C, Stillman P. What do doctors think of pharmacists treating minor ailments? Pharm J 1983; 231: 388.

10. Kirking DM, Bickley SK, Wasserman ML. Physician opinion of pharmacist-initiated change from injectable to oral administration of histamine H2-receptor antagonists. Am J Hosp Pharm 1991; 48: 1722-1727.

11. Grussing PG, Goff DA, Kraus DM, MuellerCE. Development and validation of an instrument to measure physicians' attitudes toward the clinical pharmacist's role. Drug Intell ClinPharm 1984; 18: 635-640.

12. Griffin JF. More physician-pharmacist cooperation needed. N Engl J Med 1986; 56: 115-118.

13. Ables AZ, Baughman OL, III. The clinical pharmacist as a preceptor in a family practice residency training program. Fam Med 2002; 34: 658-662.

14. Bradshaw SJ, Doucette WR. Community pharmacists as patient advocates: physician attitudes. J Am Pharm Assoc 1998; 38: 598602.

15. Nesbit F, Chaplain DC, Edwards JA Jr, Fleming GR, Harker MN, Work DR, Neelon FA. 
Counselling of patients by pharmacists. Blessing or curse? NC Med J 1995; 56: 115118.

16. Ranelli PL, June Biss J. Physicians' perceptions of communication with and responsibilities of pharmacists. Am Pharm Assoc 2000; 40: 625630.

17. Tanskanen P, Jakala J, Airaksinen M. Physicians' view on co-operation with community pharmacists in Finland. J Soc Adm Pharm 1997;14:220-9. J Soc Adm Pharm 1997; 14: 220-229.

18. Plagakis J. Don't call me, call the doc. Drug Trop 1997; 141: 67.

19. Matowe L, Abahussain EA, Al-Saffar N, Bihzad SM, Al-Foraih A, Al-Kandery AA. Physicians' perceptions and expectations of pharmacists professional duties in government hospitals in Kuwait. Med Princ Pract 2006; 15: 185-189.

20. Abduelkarem A, Sharif S. Current Levels of Interaction between the Physician and Pharmacist: A Comparative Study in Libya and UAE. Jordan J Pharm Sci 2008; 1: 146-155.
21. Awad A, Matowe L, Capps P. Medical doctors' perceptions and expectations of the role of hospital pharmacists in Sudan. Pharm World Sci 2007; 29: 557-564.

22. Dameh M. Pharmacy in the United Arab Emirates. Southern Med Review 2009; 2: 15-18.

23. Tahaineh $L M$, Wazaify $M$, bsoul-Younes $A$, Khader $Y$, Zaidan M. Perceptions, experiences, and expectations of physicians in hospital settings in Jordan regarding the role of the pharmacist. Res Social Adm Pharm 2009; 5: 63-70.

24. Hawksworth GM, Chrystyn H. Clinical pharmacy in primary care. Br J Clin Pharmacol 1998; 46: 415-420.

25. Kheir N, Zaidan M, Younes H, El Hajj M, Wilbur K, Jewesson $P$. Pharmacy Education and Practice in 13 Middle Eastern Countries. Am J Pharm Educ 2008; 72: 133.

26. Spencer JA, Edwards C. Pharmacy beyond the dispensary: general practitioners' views. BMJ 1992; 304: 1670-1672. 